\title{
Why Swedes Don't Wear Face Masks During the Pandemic-A Consequence of Blindly Trusting the Government
}

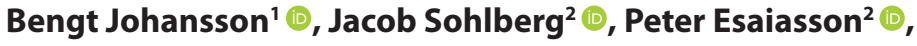 \\ and Marina Ghersetti ${ }^{1}$ (i)
}

1. Department of Journalism, Media and Communication, University of Gothenburg, Göteborg, Sweden

2. Department of Political Science, University of Gothenburg, Göteborg, Sweden

\begin{abstract}
Government trust is generally helpful for societies, especially in crisis situations, such as during the COVID-19 pandemic, because governments rely on citizens to follow directives. Worldwide, with supporting evidence accumulating, a key directive has been to wear face masks. However, in Sweden, the government has questioned their usefulness. On other behavioral recommendations, such as handwashing, the government has taken a conventional path. We rely on this non-recommendation of face masks to examine the causal impact of government trust on behavior. Based on a large Swedish survey fielded during the pandemic, we find that higher government trust reduces the likelihood of wearing face masks. In contrast, higher trust increases the likelihood of handwashing. The findings qualify the conclusion about the beneficial consequences of trust.
\end{abstract}

KEYWORDS: government trust, face masks, handwashing, Sweden, coronavirus, COVID-19

\section{ACKNOWLEDGMENT}

The research is funded by Grant \#2017-2860 from the Swedish Civil Contingencies Agency.

CONTACT Bengt Johansson (D) - E-mail: bengt.johansson@jmg.gu.se • Department of Journalism, Media and Communication • University of Gothenburg • Box 710 • SE-40530 Göteborg, Sweden 
A long-held truth in the social sciences is that high levels of citizen trust in government is conducive for democracy, in large part because it helps in generating legitimacy for authoritative decision-making (Hetherington, 2005; Marien \& Hooghe, 2011; Rothstein, 1998). The importance of trust is particularly acute during crises, when citizens are expected to follow instructions from government authorities (Christensen \& Laegreid, 2005; Siegrist \& Zingg, 2014). Thus, in order to manage crises, including the COVID-19 pandemic, governments rely on citizens to agree to even far-reaching restrictions on their personal freedoms (Devine et al., 2020; Van Bavel et al., 2020).

Taking the trust-compliance relationship as the point of departure, our paper makes two contributions to this literature. The first concerns are to address the need for closer examination of the direction of causality between trust and compliance (Siegrist \& Zingg, 2014). As will be developed, we leverage a case in which government authority instructions on protective measures deviated from the recommendations of international expertise on a key aspect, and map how citizens adopted the instructions depending on their levels of government trust. This design, with its high external validity due to the real-world situation, allows us to infer what is likely a causal impact of government trust on voluntary compliance with government instructions.

Second, the empirical case we study highlights a previously less discussed boundary condition for the trust-compliance relationship needed to facilitate crisis management. As explained below, high levels of citizen trust only help to mitigate a crisis when government recommendations are accurate and helpful. In other words, high trust in government might actually be harmful for citizens' ability to cope with a dangerous situation if the recommended measures are inadequate.

Our case is the Swedish strategy to handle the COVID-19 pandemic. Just like in other countries, Swedes were implored to follow a number of protective measures to stop the spread of the virus, whereof social distancing and handwashing were the most important. However, the instructions from the Swedish government authorities stand out with regard to the use of face masks (PHA, 2020; see also https://www.bbc.com/news/ 
world-europe-55371102). International crisis management institutions, such as the World Health Organization (WHO, 2020) and the European Centre for Disease Prevention and Control (ECDC, 2020), had repeatedly promoted face masks as a helpful protective measure, and this policy was gradually adopted by governments across the globe. By the early fall of 2020, the Swedish government was the only government in the developed world that did not recommend, or require, its citizens to wear face masks in any context (Andersson \& Aylott, 2020; Petherick et al., 2020). In fact, in the spring, statements were made that face masks could be counterproductive in certain circumstances (Expressen, 2020; PHA, 2020). If the trust-compliance relationship works as suggested in the literature, high trust in Swedish government authorities would lead to a higher likelihood of citizens complying with certain recommendations such as to wash hands carefully, but simultaneously a lower likelihood of wearing face masks.

For empirics, we draw on a web survey with a large sample of adult Swedes $(n>10,000)$ conducted in the fall of 2020 , just before and at the beginning of the second wave of the COVID-19 pandemic in Sweden. For some key variables, we also have panel data information that goes back to the first phase of the pandemic in the spring of 2020 .

\section{Literature Review}

\section{Trust in Government, Adoption of Protective Measures, and Crisis Communication}

Trust in government and government institutions is often treated as a crucial element when dealing with crises and disasters (Christensen \& Laegreid, 2005; Poortinga \& Pidgeon, 2003; Siegrist \& Zingg, 2014; Van der Weerd et al., 2011). A lack of general government trust may influence risk perceptions and undermine people's willingness/ability to mitigate risks and support risk management (Devine et al., 2020; Siegrist \& Zingg, 2014; Van der Weerd, 2011).

Health communication research conducted during previous pandemics, such as the Ebola outbreak in 2014-2016 (Blair 
et al., 2017; Morse et al., 2016), the SARS pandemic, the avian influenza, and the $\mathrm{H}_{1} \mathrm{~N}_{1}$ (swine flu) pandemic (Siegrist \& Zingg, 2014), confirm that respondents with high government trust are more inclined to take precautionary actions to protect themselves and abide recommendations to mitigate the spread of the disease. However, as Siegrist and Zingg conclude in their overview of the field, the causal interpretation of these studies is questioned since they build on weak designs for causal inferences. For example, they mainly rely on cross-sectional data without persuasive identification strategies.

Also, with regard to the COVID-19 pandemic, research indicates that trust is conducive for compliance with government recommendations, although there are exceptions (Ling Wong \& Jensen, 2020). Studies from the early phases of the pandemic observe that high trust in government institutions is associated with willingness to adopt protective measures such as social distancing, washing hands, testing for infection, and wearing face masks (Devine et al., 2020). Further, higher trust is related to higher levels of obeying regulations and recommendations (Han et al., 2020; Olsen \& Hjorth, 2020), lower mortality rates (Oksanen et al., 2020), and intention to get vaccinated (Parson Leigh et al., 2020).

To sum up, previous research theorizes that there is a causal relationship between trust in government and its institutions and citizens' compliance with protective measures. However, confidence in this assumption would be strengthened if it rested on studies using research designs more suited at establishing causality. By analyzing the contrasting government recommendations in Sweden regarding the use of face masks and handwashing during the COVID-19 pandemic, we can more precisely address the causal relationship.

Our design rests on the peculiarities of the Swedish case, where the crisis communication from the government is consistent with almost all other countries in the world regarding the importance of handwashing, but stands out when it comes to the use of face masks, which also has caused intense public debate and critique. By analyzing this contrast in recommendations, we are better 
positioned to explore what is presumably a causal effect of compliance on protective measures.

\section{Sweden: Risk Culture, COVID-19 Strategies and Crisis Communication}

Sweden is characterized by a pronounced state-oriented risk culture (Cornia et al., 2016). Government institutions are expected to effectively administer disaster prevention, mitigate ongoing crises, and to guide and inform citizens through a crisis. Furthermore, Swedish governance relies on highly independent government authorities, and the Swedish government early announced that it would follow the advice of the Public Health Agency (PHA) during the COVID-19 pandemic (Pierre, 2020). Accordingly, Sweden's strategy for handling the pandemic was designed and communicated by the PHA through frequent press conferences, interviews, and information campaigns. When we address the trust-compliance relationship in Sweden during the COVID-19 pandemic, we thus refer to trust in government authorities, not the political dimension of government. This distinction is not emphasized in previous research on trust and crisis management, mostly because government control over authorities is stronger in many countries, but also because governments in most countries may declare a state of emergency and centralize authority during a crisis. State of emergency can only be declared in Sweden during wartime (Pierre, 2020).

A prerequisite for the Swedish state-oriented risk culture is trust, and in international comparison, Sweden has high levels of both institutional and interpersonal trust (Martinsson \& Andersson, 2019; Ortiz-Ospina \& Roser, 2020), levels that increased even higher due to the rally effect during the first months of the coronavirus crisis (Esaiasson et al., 2020; Johansson \& Vigsø, 2021). The high levels of trust were also the cornerstone in the Swedish coronavirus strategy; the public was expected to voluntarily follow the recommendations of the experts (Johansson \& Vigsø, 2021).

Compared to other countries, the Swedish response to the COVID-19 pandemic was less invasive, and without a lockdown (Andersson \& Aylott, 2020; Petherick et al., 2020). Rather than 
coercive measures, the strategy has relied on advice and recommendations, many of which were similar to those in other countries. People were encouraged to wash their hands frequently and avoid social contacts, especially indoors. Importantly, the PHA never recommended, leave alone mandated, the use of face masks in Sweden. The arguments being that masks did not protect against being infected, that wearing a mask risked inducing false security and lower people's caution, and that incorrect handling of the mask might even lead to increased spreading of the virus (PHA, 2020). Even as more scientific evidence accumulated on the usefulness of masks, especially in reducing the spread from infected people to others (Chu et al., 2020), the PHA maintained that the evidence was insufficient. In this respect, Sweden's strategy differed remarkably from countries worldwide (see Figure 1).

\section{FIGURE 1 Face Covering Policies During the COVID-19 Pandemic,} Oct 26, 2020

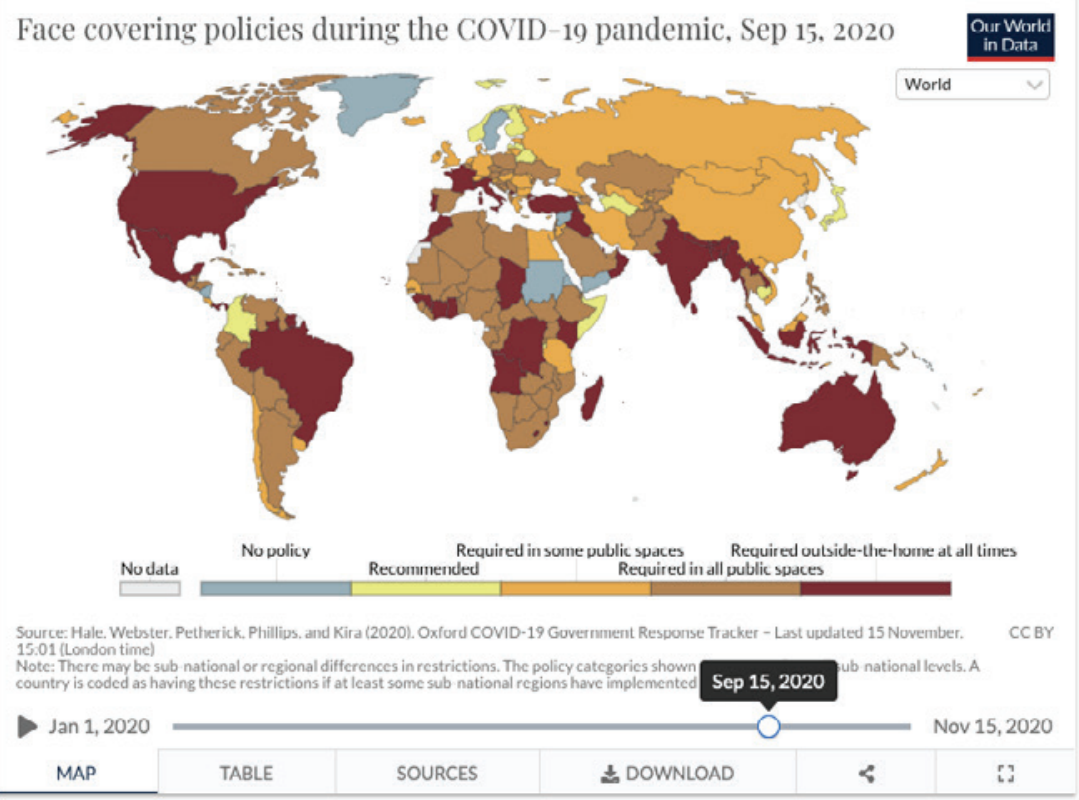


While we do not have specific evidence from the survey, based on previous research on information seeking and news media consumption, we can assume that Swedes were aware of the specific recommendations by the PHA. Not only were the agency's press conferences followed directly by large audiences, but they were also reported on widely in the news media. With Swedes being high news consumers in general, and especially during a crisis (Andersson, 2020), it is likely that people knew of the recommendations and how they diverged from those in other countries. Not at least since citizens could compare the non-use of face masks in Sweden with media reporting of people using face masks in other countries. In addition, the PHA's position on the use of face masks was publicly debated, and the non-use of face masks was the most frequently recurring question from journalists during the daily press conferences (Dahlgren, 2021).

\section{Hypotheses}

Against this background, we can explicate the logic of our research design. Since trust generally increases compliance, and since governments want their citizens to protect themselves from the coronavirus, we expect that Swedes with higher trust in government will willingly comply with the action recommended by the government authorities, such as frequent handwashing. However, and this is why the Swedish case is informative about the potential causal character of the trust-compliance relationship, when it comes to wearing face masks, trust in government is expected to lead to other behavioral consequences in Sweden than in the rest of the world. Since there is no recommendation from the government authorities to wear face masks in public places, trusting Swedes will not make the extra inconvenience of wearing them. More formally, our hypotheses are:

H1: Swedes with higher trust in government are more likely to wash their hands more frequently than Swedes with lower trust in government.

H2: Swedes with higher trust in government are less likely to wear face masks in public than are Swedes with lower trust in government. 


\section{Method}

\section{Participants}

Our data is from the Citizen Panel, which is maintained by the Laboratory of Opinion Research (LORE) at the SOM-institute, University of Gothenburg. The panel includes around 75,000 adult members from all over Sweden. A smaller portion of the panel has been recruited through probability-based methods, but an overwhelming majority are self-recruited. Most panelists participate in surveys and experiments twice a year (www.gu.se/som-institute). We invited a portion of the panel to our survey. The survey was fielded between September 15 and October 26, 2020, and was completed by 10,226 respondents. We also leverage that some survey questions were asked to the same individuals in a previous panel-wave in February and March 2020.

As with the panel at large, our sample is made up of opt-in participants. For example, the sample has a higher educational attainment than the Swedish population and is therefore not representative in this respect. Therefore, point estimates should be interpreted with caution. However, what is more important is that there is variation in the variables, enabling us to examine the relationship between our key factors. Descriptive statistics are available in Appendix A1.

\section{Measures and Analytical Strategy}

Our outcome variables are two pandemic-relevant behaviors: handwashing and face mask wearing. Handwashing was measured by asking, "Last month, were you more careful with hand hygiene?" To measure the usage of face masks, we asked the respondents, "Last month, did you wear a face mask?" For both types of behavior, respondents could choose between "yes" or "no" as response options. Eighty-eight percent said they were more careful with handwashing while 12 percent reported that they were not. Nineteen percent had worn a face mask and 81 percent had not. In the analysis below, yes is coded as 1 and no as 0 .

One way of thinking about the analytical approach is that it shares similarities with a within-subjects design that has occurred naturally in the Swedish context. In one treatment, subjects are 
given the recommendation that they should do something to reduce the spread of COVID-19 and, in another treatment, they are not recommended to act in a certain way. Obviously, in a within-subjects design, the outcome variable should be the same. In our case, it is admittedly not-one is about handwashing and the other about wearing face masks-but to the extent that they are both behaviors that aim at reducing the spread, they are equivalent.

Still, since we are cognizant that logic of the within-subject design might not apply in this case, we include variables in the models that aim at reducing omitted variable bias. Specifically, we estimate three models for each outcome. First, we report the effect of government trust while including interpersonal trust as a covariate in the model. Interpersonal trust is included since the two trust concepts are related (Vallier, 2019), and we want to reduce the risk of omitted variable bias due to this factor. Second, we add other covariates as controls. They include several background factors such as age, sex, education, and so on. Moreover, we control for left-right ideology, party support, and news consumption (domestic and foreign). Third, we study the effects of government trust while controlling for pre-crisis levels of government trust. Here, we rely on the panel components of the data. In addition, we test if the effects on the two dependent variables are different.

We measured trust in government, our main independent variable, with the following question: "Generally speaking, how much trust do you have in Swedish government authorities?" Five response options were available ("Very low," "Rather low," "Neither low nor high," "Rather high," and "Very high."). Unless otherwise noted, this and other variables have been re-coded to range from o to 1 , with higher values indicating more trust $(M=0.70$, $S D=0.24)$.

Interpersonal trust was measured with the following question: "In your opinion, to what extent is it generally possible to trust people?" The endpoints were labelled with "People cannot generally be trusted" and "People can generally be trusted." Five response options were available $(M=0.75, S D=0.24)$. We measured exposure to foreign media on the coronavirus by asking respondents the extent to which they search for information about the coronavirus in foreign media. Five response options were 
available, ranging from several times a day to never. Exposure to domestic media on the coronavirus was measured with a similar question and response option, but it asked about domestic media instead. Higher values indicate more information search. Leftright ideology was measured by asking respondents to place themselves on an 11-point scale where endpoints (far left and far right) and the midpoint (neither left nor right) were labelled. Higher values indicate more right-leaning. Party support is dummy coded where government supporters are the baseline. Opposition party support and other party/don't know/ref are dummies in the model. Sex is dummy coded where female is the baseline and male $=1$. Age of the respondent is measured with six categories. Education indicates the respondent's highest educational attainment. The variable has nine categories, with higher values indicating more education. Location is dummy coded with "Large city (central)" as the baseline. Dummy categories are "Large city (suburb)," "City (central)," "City (outskirts)," "Town," "Small town," and "Countryside." Foreign-born is a dummy variable indicating the country of birth, where born in Sweden is the baseline. Government trust lagged is trust in institutions measured the same as above, but in February or March $2020(M=0.64, S D=0.25)$. Interpersonal trust lagged measures social trust, also in February or March with the same questions and options as above $(M=0.73, S D=0.23)$. Table A1 has additional details on frequency distributions by variables.

\section{Results}

We expect that government trust will have contrasting effects on washing hands and wearing face masks. Because of the binary outcome variables, we rely on logistic regression for estimates. Turning first to handwashing, our results show that higher government trust is associated with greater likelihood of more careful hand hygiene, which yields support for $\mathrm{H}_{1}$. For example, we find that the average likelihood of careful hand hygiene at the lowest level of trust is 0.82 while it is 0.91 at the highest level of trust. The odds ratio is 2.108 (95\% CI $[1.618,2.748], p<0.001)$ according to the results in model 1 of Table 1 . The results are also illustrated by Figure 2. There seems to be somewhat of a reduced effect when we 
include more covariates (models 2 and 3), but the effect of government trust is largely the same, and still statistically significant $(p<0.05)$ in both models. As expected, people who trust government authorities tend to follow its recommendations.

\section{FIGURE 2 Probability of Careful Hand Hygiene by Government Trust}

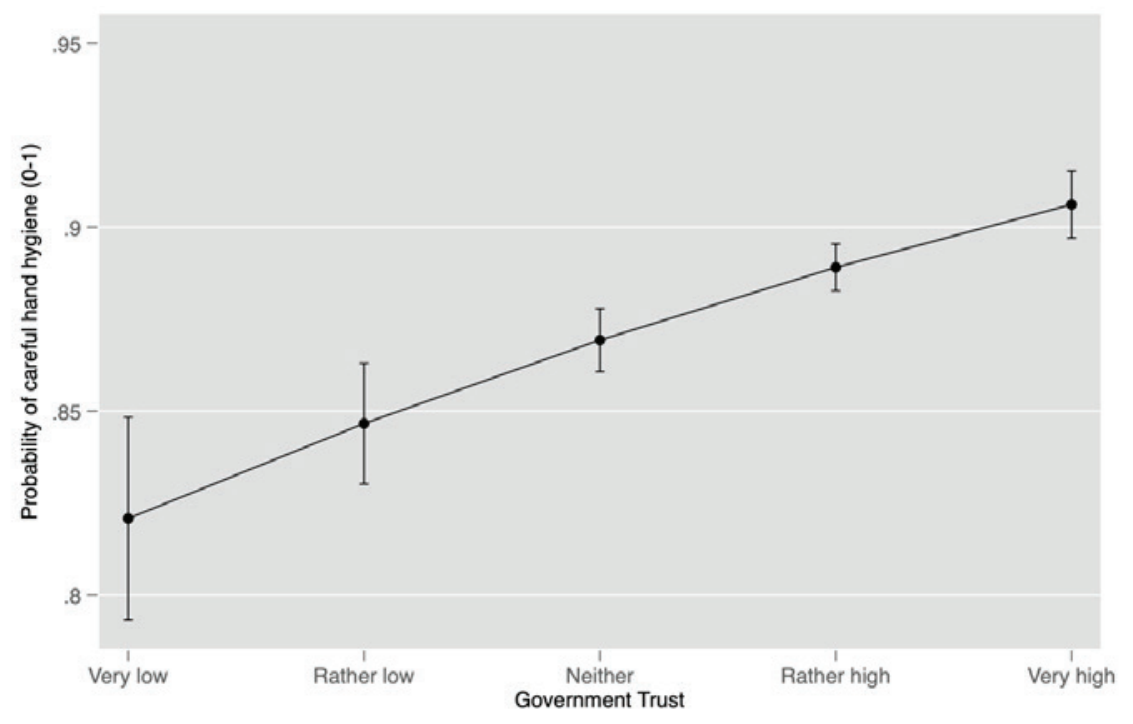

Next, we turn to $\mathrm{H}_{2}$ and the likelihood of wearing face masks. Figure 3 shows that higher government trust is associated with a lower likelihood of wearing face masks. For example, an individual at the lowest end of the trust scale ("Very low") had a probability of 0.33 whereas someone at the highest end ("Very high") had a probability of 0.14 . The odds ratio of the estimate is 0.335 (CI: $0.270-0.417, p<0.001$ ). This provides support for $\mathrm{H} 2$. In other words, for this type of behavior, trust in government authorities has the opposite effect compared to the effect on handwashing. These results are robust to the inclusion of additional control variables, as the results in models 2 and 3 show. The figure is based on the first model of Table 2, where only interpersonal trust is included as a control variable. It is especially noteworthy that the effect is substantially the same even when prior levels of trust are taken into account (model 3 ) since this model reduces the risk of omitted variable bias. 


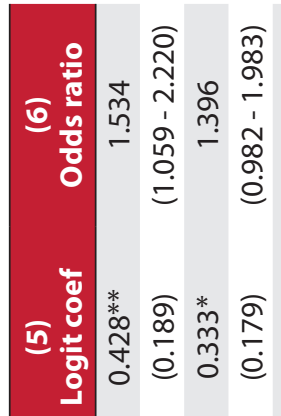

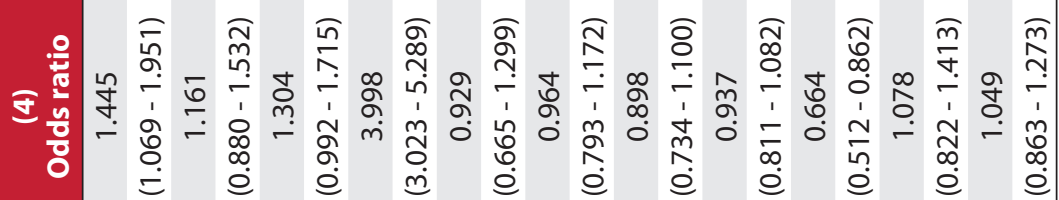

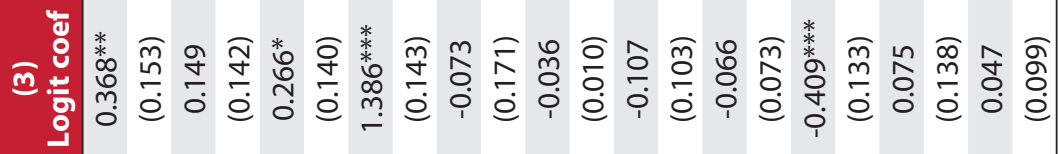

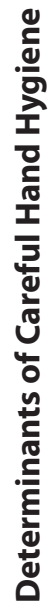

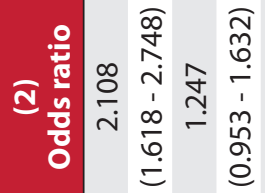

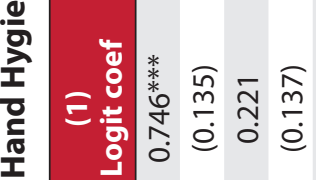

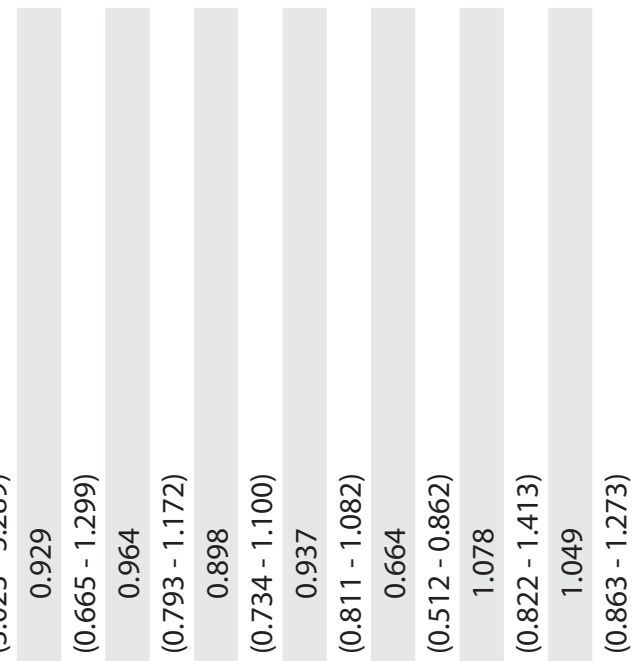




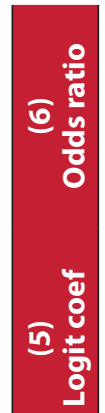

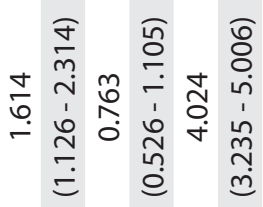

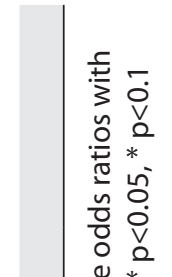

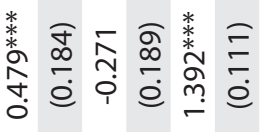

ลิ

을

\%

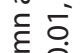

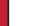

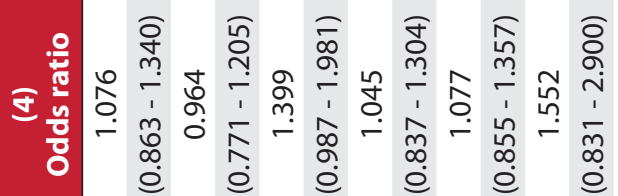

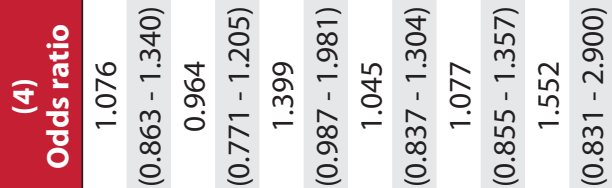

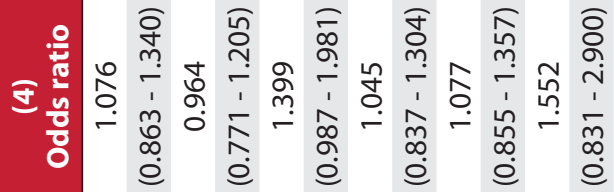

m.

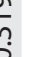




\section{FIGURE 3 Probability of Wearing Face Mask by Government Trust}

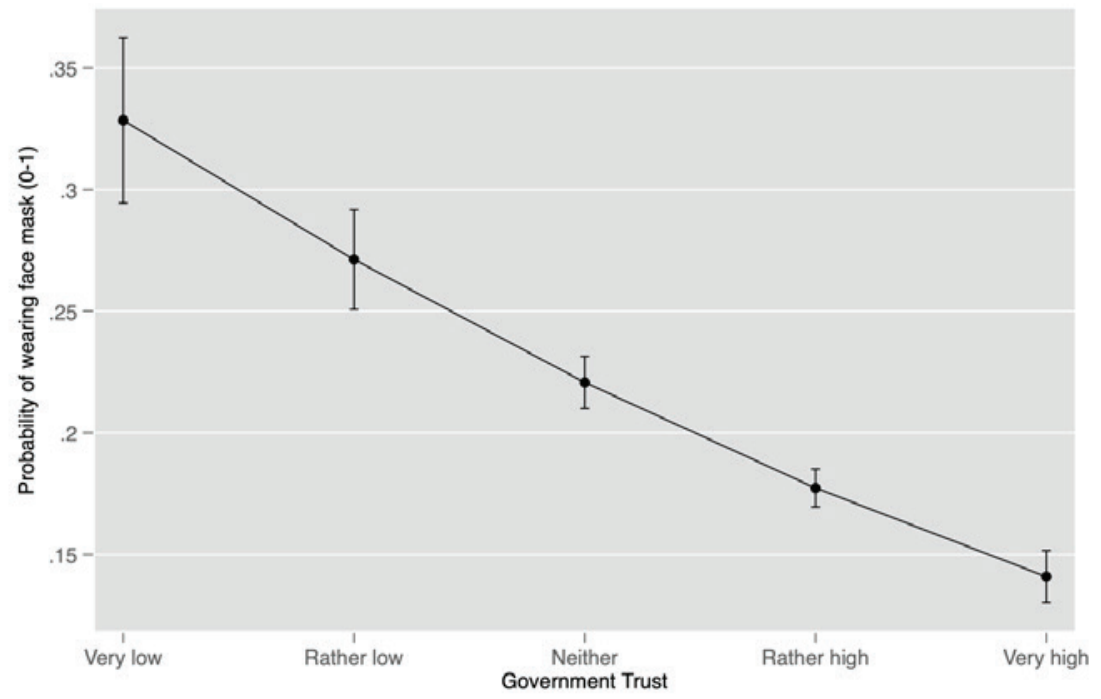

We are studying two behavioral outcomes where the government has given contrasting recommendations. Besides finding that the effects are statistically significant on their own and in opposing directions, we complement this analysis by simultaneously estimating the models and testing if the coefficients are different. The $\chi 2$-test is statistically significant at $\mathrm{p}<0.001$, thus rejecting the null hypothesis that they are similar, which again affirms the contrasting effects noted above.

\section{Other Determinants of Washing Hands and Wearing Face Masks}

Besides government trust, other factors also appear to play a role in handwashing. Table 1 (model 2) shows that people who pay more attention to domestic media's coverage of the coronavirus are more likely to engage in careful handwashing (OR: 3.998, $p<0.001)$. Given that domestic media have devoted a substantial portion of their coverage to the importance of hand hygiene, mirroring the position of relevant institutions, this finding has a plausible explanation. In addition, this exploratory analysis of statistically significant results indicates that older individuals are less likely to wash hands than younger individuals are (OR: $0.664, p=0.002)$. 


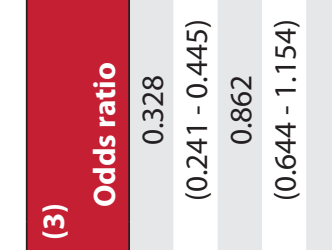

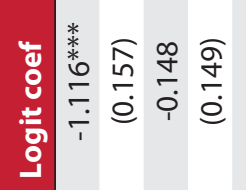

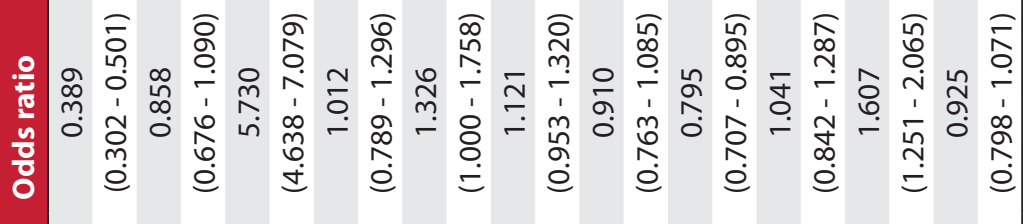
บ

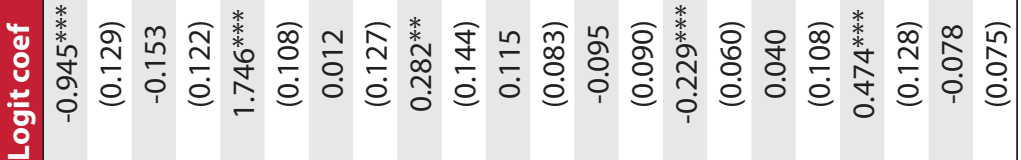

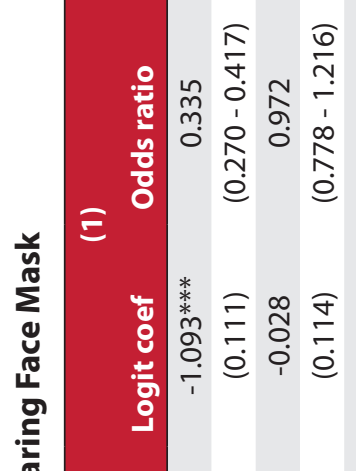

造

N

붐 $\leftarrow$

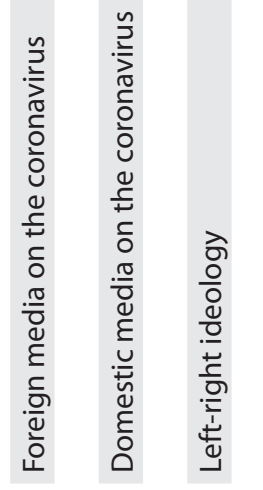

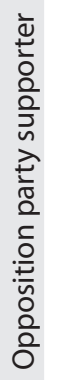

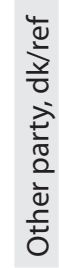




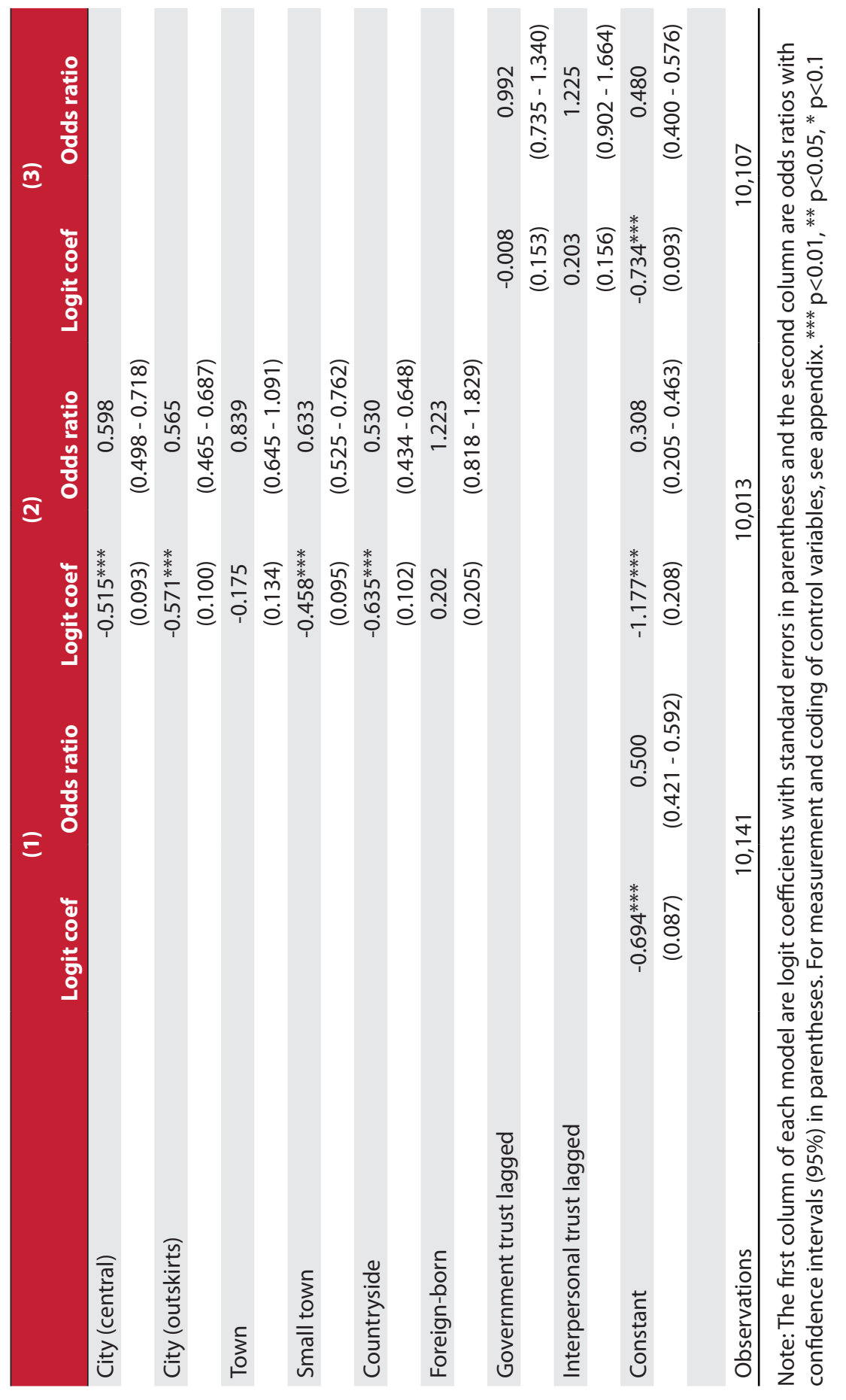


As for other factors associated with wearing face masks, we find that men seem less likely to wear masks than women $(\mathrm{OR}=$ $0.795, p=0.001$ ) and that individuals who consume a great deal of foreign media appear more likely to wear masks than those who do $\operatorname{not}(\mathrm{OR}=5.730, p<0.001)$. Moreover, mask wearing seems more common among highly educated people $(\mathrm{OR}=1.607, p<0.001)$ and among people on the right of the ideological spectrum $(\mathrm{OR}=$ $1.326, p=0.05$ ). In addition, the findings indicate that individuals living outside the centers of large cities (the baseline category) are generally less likely to wear masks.

Of these findings, it is perhaps the relationship between foreign media consumption and wearing face masks that is the most intriguing. It seems as people who get their information from abroad, where face masks are generally recommended, tend to adjust their face mask behavior accordingly.

\section{Discussion}

To investigate the causal effect of government trust on compliance with government instructions, we leverage a peculiarity in the Swedish strategy in response to the COVID-19 pandemic: citizens are recommended to wash their hands frequently, but are not encouraged to wear face masks. From this, we derive two predictions about differential behavior: If government instructions impact causally upon the precautionary measures individuals are willing to undertake, citizens with higher trust in government will be more likely to be careful with hand hygiene than citizens with lower trust in government, but less likely to wear face masks. Our findings from a large and diverse sample of Swedish adults generate precisely this pattern. The results hold under control for prior levels of trust in government, and a host of potential confounding variables like interpersonal trust, partisanship, news media use, education, age, and gender.

However, as trust levels are observed and not induced at random, our findings are not conclusive, but with the logic of the within-subjects design and statistical adjustments, they strengthen the belief in a causal interpretation of the trust-compliance relationship that frequently appears in the literature on risk and crisis 
management/communication. It does indeed seem that high levels of government trust is conducive for the citizens' willingness to follow government recommendations during crises.

Consequently, the government's crisis communication will have extensive possibilities to change citizen behavior during a crisis, at least in a state-oriented risk culture like Sweden. Further, the government can then even recommend and effectively implement protective measures, which contradict advice given by international health organizations like the WHO/ECDC, and citizen's mediated experiences of the situation in other countries.

In relation to this, we return to the prerequisite for effective crisis management that we mentioned in the introduction-that the government provides the best possible advice to its citizens. When citizens put their trust in the government and follow its recommendations, they rely on the government's ability to both evaluate risks and to put citizen's interest first (Hamm et al., 2019). In essence, people use the government as a source cue to simplify a complex information environment. For this approach to work, enabling a form of low-information rationality (see Popkin, 1991) the quality of the recommendations is crucial. If recommended protective measures turn out to be ineffective, or even detrimental, high trust becomes counterproductive in citizens' attempts to cope with a crisis. High trusting citizens will consequently be less capable compared with low trusting citizens to protect themselves and others if they follow government recommendations, which underlines the normatively problematic aspects of blind trust.

The possible harm of giving inadequate advice also relates to the literature on risk and crisis communication ethics. According to the precautionary principle, measures should be taken to eliminate risks (Leslie, 2006) and significant choice so that citizens, based on accurate and relevant information, may be able to protect themselves, or at least make an informed choice about what to do (Ulmer et al., 2011). Since trust is such a powerful tool in risk and crisis communication, practitioners should acknowledge the great responsibility that comes with this mechanism. What if the given recommendations are inaccurate? And if so, what are the consequences for government trust and future possibilities of effective crisis communication? 
There are, of course, several limitations of this study. The question of causality in the trust-compliance relation has already been discussed, so also consequences of the non-probability sample. Further, while the study has variation in measures of recommended and non-recommended behavior, we lack appropriate questions about other types of behavior. For example, additional measures of adopting recommended social distancing would have strengthened the analysis of the trust-compliance relationship. Furthermore, the investigation of the trust-compliance relationship in this study is limited to a state-oriented risk culture and one could assume that the effectiveness of communicating protective measures is lower in risk cultures with lower institutional trust (Cornia et al., 2016). Also, one should acknowledge the Swedish system of governance, having independent government authorities. The combination of independent government authorities and a tradition of these agencies being responsible for managing the crises might have strengthened the citizens' willingness to follow recommendations. Since government authorities are independent from the political side of government, the issue of face masks was never politicized in a way as we have seen in other countries, like the United States. In order to understand the effectiveness of trust in crisis communication, we need therefore investigate how the trust-compliance relationship plays out in countries where crisis management is more strongly connected to the prime minister/ president and the cabinet. Therefore, even if the Swedish case gives us some important takeaways on the trust-compliance relationship, and the ethical implications of this relationship, we need to further investigate the scope and limitation of trust in crisis communication.

\section{ORCID}

Bengt Johansson (ㄱ) https://orcid.org/oooo-0002-8980-1677

Jacob Sohlberg (1) https://orcid.org/oooo-0002-3195-6895

Peter Esaiasson (i) https://orcid.org/oooo-0001-8572-5462

Marina Ghersetti (1) https://orcid.org/oooo-0001-9670-8983 


\section{References}

Andersson, S., \& Aylott, N. (2020). Sweden and coronavirus: Unexceptional exceptionalism Soc. Sci., 9(12), 232. https://doi. org/10.3390/socsci9120232

Andersson, U. (2020). Nyhetsvanor under coronapandemin [News consumption during the corona pandemic]. The SOM-Institute: University of Gothenburg. https://web.archive. org/web/20210125024708/https://www.gu.se/nyheter/ forandrade-nyhetsvanor-under-corona

Blair R. A., Morse, B. S., \& Tsai, L. L. (2017). Public health and public trust: Survey evidence from the Ebola Virus disease epidemic in Liberia. Social Science \& Medicine, 172, 89-97. https://doi.org/10.1016/j.socscimed.2016.11.016

Christensen, T., \& Laegreid, P. (2005). Trust in government: The relative importance of service satisfaction, political factors, and demography. Public Performance \& Management Review, 28(4), 487-511. https://doi.org/10.1080/15309576.2005.11051 848

Chu, D. K., Akl, E. A., Duda, S., Solo, K., Yaacoub, S., \& Schünemann, H. J. (2020). Physical distancing, facemasks, and eye protection to prevent person-to-person transmission of SARS-CoV-2 and COVID-19: A systematic review and meta-analysis. The Lancet, 395(10242), 1973-1987. https:// doi.org/10.1016/So140-6736(20)31142-9

Cornia, A., Dressel, K., \& Pfeil, P. (2016). Risk cultures and dominant approaches towards disasters in seven European countries. Journal of Risk Research, 19(3), 288-304. https://doi.org/ 10.1080/13669877.2014.961520

Dahlgren, P. M. (2021). Ställde journalisterna kritiska frågor under Folkhälsomyndighetens presskonferenser? [Did the journalist ask critical questions during PHA:s press conferences?]. In B. Johansson, \& L. Truedson (Eds.), Journalistik $i$ coronans tid [Journalism in the age of Corona], (pp. 56-72). Institutet för Mediestudier.

Devine, D., Gaskell, J., Jennings, W., \& Stoker, G. (2020). Trust and the coronavirus pandemic: What are the consequences of and for trust? An early review of the literature. Political Studies Review, 1-12. https://doi.org/10.1177/1478929920948684 
ECDC. (2020). Infographic: Using face masks in the community. https://web.archive.org/web/20200414134154/https://www. ecdc.europa.eu/en/publications-data/infographicusing-face-masks-community

Esaiasson, P., J. Sohlberg, M. Ghersetti, and B. Johansson. 2020. "How the Coronavirus Crisis Affects Citizen Trust in Government Institutions and in Unknown Others-Evidence from the Swedish Experiment." European Journal of Political Research. https://doi.org/10.1111/1475-6765.12419

Expressen. (2020). https://www.expressen.se/nyheter/tegnell sagar-munskydd-i-tysk-intervju-farligt/

Hamm, J. A., Smidt, C., \& Mayer, R. C. (2019). Understanding the psychological nature and mechanisms of political trust. PLOS ONE 14(5), e0215835. https://doi.org/10.1371/journal. pone.0215835

Han, Q., Zheng, B., Cristea M., Agostini, M., Belanger, J., Gutzkow, B., Kreienkamp, J., PsyCorona Team, \& Leander, P. (2020). Trust in government and its associations with health behaviour and prosocial behaviour during the COVID-19 pandemic. PsyArXiv. Epub ahead of print 29 June. https://doi. org/10.31234/osf.io/p5gns

Hetherington, M. J. (2005). Declining political trust and the demise of American liberalism. Princeton University Press.

Johansson, B., \& Vigsø, O. (2021). Sweden: Lone hero of stubborn outlier? In D. Lilleker, I. A. Coman, M. Gregor, \& E. Novelli (Eds.), Political Communication and COVID-19: Governance and Rhetoric in Times of Crisis (pp. 155-164). London: Routledge.

Leslie, M. (2006). Fear and coughing in Toronto: SARS and the uses of risk. Canadian Journal of Communication. 31, 367-389. https://doi.org/10.22230/cjc.2006v31n2a1544

Ling Wong, C. M., \& Jensen, O. (2020). The paradox of trust: Perceived risk and public compliance during the COVID19 pandemic in Singapore. Journal of Risk Research, 23(7-8), 1021-1030. https://doi.org/10.1080/13669877.2020.1756386

Marien, S., \& Hooghe, M. (2011). Does political trust matter? An empirical investigation into the relation between political trust and support for law compliance. European Journal of Political Research, 50(2), 267-291. https://doi.org/10.1111/j.14756765.2010.01930.x 
Martinsson, J., \& Andersson, U. (2019). Swedish trends 19862018. https://web.archive.org/web/20200210000059/https:// som.gu.se/digitalAssets/1732/1732590_7.-swedish-trends1986-2018.pdf

Morse, B., Grépin K. A., Blair R. A., \& Tsai, L. (2016). Patterns of demand for non-Ebola health services during and after the Ebola outbreak: Panel survey evidence from Monrovia, Liberia. BMJ Global Health, 1:eooooo7. https://doi.org/10.1136/bmjgh2015-000007

Oksanen, A., Kaakinen, M., Latikka R., Savolainen, L., Savela, N., \& Koivula, A. (2020). Regulation and trust: 3-month follow-up study on COVID-19 mortality in 25 European countries. JMIR Public Health and Surveillance, 6(2): e19218. https://doi. org/10.2196/19218

Olsen, A. L., \& Hjorth, F. (2020). Willingness to distance in the COVID-19. OSF Preprints. https://osf.io/xpwg2/

Ortiz-Ospina, E., \& Roser, M. (2020). Trust. Our world in data. https://web.archive.org/web/20200225142410/https:// ourworldindata.org/trust

Parsons Leigh, J., Fiest, K., Brundin-Mather, R., Plotnikoff, K., Soo A., Sypes E. E., Whalen-Browne, L., Ahmed, S. B., Burns, K. E. A., Fox-Robichaud, A., Kupsch, S., Longmore, S., Murthy, S., Niven, D. J., Rochwerg, B., \& Stelfox, H. T. (2020). A national cross-sectional survey of public perceptions of the COVID-19 pandemic: Self-reported beliefs, knowledge, and behaviors. PLoS ONE, 15(10), eo241259. https://doi.org/10.1371/journal. pone.0241259

Petherick, A., Hale, T., Phillips, T., \& Webster, S. (2020). Variation in government responses to COVID-19. https://www.bsg. ox.ac.uk/research/publications/variation-governmentresponses-covid-19

PHA 2020: What is your advice regarding face masks? https:// web.archive.org/web/20200814045353/https://www.folk halsomyndigheten.se/the-public-health-agency-of-sweden/ communicable-disease-control/covid-19/prevention

Pierre, J. (2020). Nudges against pandemics: Sweden's COVID-19 containment strategy in perspective. Policy and Society, 39(3), 478-493. https://doi.org/10.1080/14494035.2020.1783787 
Poortinga, W., \& Pidgeon, N. F. (2003). Exploring the dimensionality of trust in risk regulation. Risk Analysis, 23, 961-972. https://doi.org/10.1111/1539-6924.00373

Popkin, S. L. (1991). The reasoning voter: Communication and persuasion in presidential campaigns. University of Chicago Press.

Rothstein, B. (1998). Just institutions matter: The moral and political logic of the universal welfare state. Cambridge University Press.

Siegrist, M., \& Zingg, A. (2014). The role of public trust during pandemics. European Psychologist, 19(1), 23-32. https://doi. org/10.1027/1016-9040/a0o0169

Ulmer, R. R., Sellnow T. L., \& Seeger, M. W. (2011). Effective crisis communication: Moving from crisis to opportunity. SAGE.

Vallier, K. (2019). Social and political trust: Concepts, causes, and consequences. https://web.archive.org/web/20210412155633/ https://www.niskanencenter.org/wp-content/uploads/ old_uploads/2019/05/Vallier-Social-and-Political-TrustNiskanen.pdf

Van Bavel, J. J., Baicker, K., Boggio P. S., Capraro, V., Cichocka, A., Cikara, M., Crockett, M. J., Crum, A. J., Douglas, K. M., Druckman, J. N., Drury, J., Dube, O., Ellemers, N., Finkel, E. J., Fowler, J. H., Gelfand, M., Han, S., Haslam, S. A., Jetten, J. . . . Willer, R. (2020). Using social and behavioural science to support COVID-19 pandemic response. Nature Human Behaviour 4, 460-471. https://doi.org/10.1038/s41562-020-0884-Z

Van der Weerd, W., Timmermans, D. R., Beaujean, D. J., Oudhoff, J., \& van Steenbergen, J. E. (2011). Monitoring the level of government trust, risk perception and intention of the general public to adopt protective measures during the influenza A $\left(\mathrm{H}_{1} \mathrm{~N}_{1}\right)$ pandemic in the Netherlands. BMC Public Health 11, 575. https://doi.org/10.1186/1471-2458-11-575

WHO. (2020). Coronavirus disease (COVID-19) advice for the public: When and how to use masks. https://web.archive.org/ web/20201202031042/https://www.who.int/emergencies/ diseases/novel-coronavirus-2019/advice-for-public/whenand-how-to-use-masks 


\section{APPENDIX TABLE A1 Descriptive Statistics}

\begin{tabular}{|c|c|c|c|c|c|}
\hline Variable/Options & Freq. & Percent & Variable/Options & Freq. & Percent \\
\hline Used face mask last month & & & Left-right ideology & & \\
\hline No & 8,229 & 81.09 & 0 Far left & 399 & 3.91 \\
\hline Yes & 1,919 & 18.91 & 1 & 519 & 5.09 \\
\hline \multirow[t]{2}{*}{ Total } & 10,148 & 100.00 & 2 & 1,142 & 11.20 \\
\hline & & & 3 & 1,326 & 13.00 \\
\hline Careful with hand hygiene & & & 4 & 1,158 & 11.35 \\
\hline No & 1,181 & 11.65 & 5 Neither left nor right & 1,332 & 13.06 \\
\hline Yes & 8,957 & 88.35 & 6 & 1,075 & 10.54 \\
\hline \multirow[t]{2}{*}{ Total } & 10,138 & 100.00 & 7 & 1,409 & 13.81 \\
\hline & & & 8 & 1,204 & 11.80 \\
\hline Government trust & & & 9 & 368 & 3.61 \\
\hline Very low & 293 & 2.87 & 10 Far right & 268 & 2.63 \\
\hline Rather low & 940 & 9.21 & Total & 10,200 & 100.00 \\
\hline Neither low nor high & 1,416 & 13.87 & & & \\
\hline Rather high & 5,472 & 53.60 & Party support & & \\
\hline Very high & 2,088 & 20.45 & Government & 5,282 & 51.90 \\
\hline \multirow[t]{2}{*}{ Total } & 10,209 & 100.00 & Opposition & 3,591 & 35.28 \\
\hline & & & Other, Don't know, Refusal & 1,305 & 12.82 \\
\hline Interpersonal trust & & & Total & 10,178 & 100.00 \\
\hline 1 People cannot generally be trusted & 212 & 2.08 & & & \\
\hline 2 & 562 & 5.51 & Sex & & \\
\hline 3 & 1,850 & 18.15 & Female & 3,230 & 31.63 \\
\hline 4 & 3,971 & 38.96 & Male & 6,981 & 68.37 \\
\hline 5 People can generally be trusted & 3,598 & 35.30 & Total & 10,211 & 100.00 \\
\hline \multirow[t]{2}{*}{ Total } & 10,193 & 100.00 & & & \\
\hline & & & Age & & \\
\hline Government trust (Feb/Mar) & & & $<30$ & 189 & 1.85 \\
\hline Very low & 377 & 3.69 & $30-39$ & 650 & 6.36 \\
\hline Rather low & 1,356 & 13.29 & $40-49$ & 1,005 & 9.83 \\
\hline Neither low nor high & 1,773 & 17.38 & $50-59$ & 2,829 & 27.66 \\
\hline Rather high & 5,323 & 52.17 & $60-69$ & 2,585 & 25.28 \\
\hline Very high & 1,374 & 13.47 & $\geq 70$ & 2,968 & 29.02 \\
\hline Total & 10,203 & 100.00 & Total & 10,226 & 100.00 \\
\hline Interpersonal trust (Feb/Mar) & & & Highest level of education & & \\
\hline 1 People cannot generally be trusted & 137 & 1.34 & Not completed elementary school & 9 & 0.09 \\
\hline 2 & 630 & 6.18 & Completed elementary school & 287 & 2.81 \\
\hline 3 & 1,839 & 18.05 & High school, $<3$ years & 640 & 6.26 \\
\hline 4 & 4,482 & 43.98 & High school, $\geq 3$ years & 763 & 7.46 \\
\hline 5 People can generally be trusted & 3,103 & 30.45 & Post-secondary education, $<3$ years & 727 & 7.11 \\
\hline \multirow[t]{2}{*}{ Total } & 10,191 & 100.00 & Post-secondary education, $\geq 3$ years & 267 & 2.61 \\
\hline & & & College/University, $<3$ years & 1,064 & 10.41 \\
\hline Coronavirus info search: Foreign media & & & College/University, $\geq 3$ years & 5,813 & 56.85 \\
\hline Never & 3,209 & 31.66 & Doctoral degree & 655 & 6.41 \\
\hline Rarely & 3,534 & 34.87 & Total & 10,225 & 100.00 \\
\hline Once a week & 2,057 & 20.29 & & & \\
\hline Daily & 1,104 & 10.89 & Location & & \\
\hline Several times a day & 232 & 2.29 & Large city (central) & 1,887 & 18.46 \\
\hline \multirow[t]{2}{*}{ Total } & 10,136 & 100.00 & Large city (suburb) & 2,434 & 23.81 \\
\hline & & & City (central) & 1,482 & 14.50 \\
\hline Coronavirus information search: Swedish media & & & City (outskirts) & 1,323 & 12.94 \\
\hline Never & 307 & 3.02 & Town & 468 & 4.58 \\
\hline Rarely & 1,543 & 15.17 & Small town & 1,414 & 13.83 \\
\hline Once a week & 2,910 & 28.61 & Countryside & 1,216 & 11.89 \\
\hline Daily & 4,322 & 42.49 & Total & 10,224 & 100.00 \\
\hline Several times a day & 1,090 & 10.72 & & & \\
\hline \multirow[t]{4}{*}{ Total } & 10,172 & 100.00 & Country of birth & & \\
\hline & & & Sweden & 10,079 & 98.57 \\
\hline & & & Foreign & 146 & 1.43 \\
\hline & & & Total & 10,225 & 100.00 \\
\hline
\end{tabular}

